\title{
Pesquisa de anticorpos anti Toxoplasma gondii em fluidos intra-oculares (humor vítreo e humor aquoso) de pacientes com toxoplasmose ocular, na Cidade de Belém, PA
}

\author{
Research on antibodies anti toxoplasma gondii in intraocular fluids \\ (Aqueous and vitreous humor) from patients with ocular toxoplasmosis, \\ in the City of Belém, Pará State
}

\author{
Ediclei Lima do Carmo ${ }^{1}$, Edmundo Frota Almeida ${ }^{2}$, Cléa Nazaré Bichara ${ }^{3}$ \\ e Marinete Marins Póvoa ${ }^{1}$
}

\section{RESUM0}

Foi realizada pesquisa de anticorpos IgG, IgM e IgA anti-Toxoplasma gondii no soro e fluidos intra-oculares (humor aquoso e vítreo) de pacientes com toxoplasmose ocular. A partir dos resultados obtidos verificou-se que anticorpos IgG e IgA intraocular anti-Toxoplasma gondii podem vir a ser importantes marcadores no diagnóstico de toxoplasmose ocular. Palavras-chaves: Toxoplasmose ocular. Anticorpos. Humor vítreo. Humor aquoso.

\begin{abstract}
Tests were performed for antibodies IgG, IgM and IgA anti-Toxoplasma gondii antibodies in serum and intraocular fluids (Aqueous and vitreous humor) from patients with ocular toxoplasmosis. By the results obtained, it was verified that intraocular IgG and IgA anti-Toxoplasma gondii antibodies can be important markers for the diagnosis of ocular toxoplasmosis.
\end{abstract}

Key-words: Ocular toxoplasmosis. Antibodies. Vitreous humor. Aqueous humor.

A toxoplasmose, infecção causada pelo Toxoplasma gondii, é uma das protozooses mais comuns em todo o mundo, apresentando diferentes formas clínicas e dentre elas a ocular. Esta forma é uma das mais importantes causas mundiais de uveítes posteriores ${ }^{115}$. A forma ocular de toxoplasmose pode ser de origem congênita com manifestações clínicas precoces ou tardias, ou ainda ser adquirida após 0 nascimento. A manifestação ocular mais comum é a retinocoroidite granulomatosa necrotizante que pode vir acompanhada de outras alterações oculares ${ }^{581214}$. 0 diagnóstico da toxoplasmose ocular é presuntivo, baseando-se na análise conjunta do quadro clínico observado, testes sorológicos e exclusão de outras etiologias como sífilis, CMV, toxocaríase e outras?.
Devido a gravidade e irreversibilidade das lesões causadas pelo T. gondii, o diagnóstico precoce dessa infecção é de fundamental importância para que seja possível aplicar a intervenção adequada, principalmente nos casos em que 0 quadro clínico e os resultados sorológicos não são conclusivos ${ }^{19}$.

0 objetivo desse estudo foi realizar a pesquisa de anticorpos anti T. gondii ( IgG, IgMe IgA) nos fluidos intra-oculares ( humor vítreo e humor aquoso) de pacientes com toxoplasmose ocular.

A amostra estudada foi constituída por 11 pacientes adultos, de ambos os sexos, encaminhados por seus respectivos oftalmologistas ao Programa de Toxoplasmose do Instituto Evandro Chagas, com diagnóstico clínico de toxoplasmose ocular.

\footnotetext{
1. Programa de Toxoplasmose do Instituto Evandro Chagas da Secretaria de Vigilância em Saúde, Ministério da Saúde, Belém, PA. 2. Clínica de Olhos do Pará, Belém, PA. 3. Núcleo de Medicina Tropical da Universidade Federal do Pará, Belém, PA. Suporte Financeiro: Instituto Evandro Chagas/SVS-MS, Projeto RENOR/FADESP ( № 249).

Endereço para correspondência: Dr. Ediclei Lima do Carmo. Seção de Parasitologia/Instituto Evandro Chagas. Rodovia BR 316 -KM 07 s/nº , Bairro Levilândia, 66090-000 Belém, PA.

Tel: 5591 214-2148, Fax: 5591 214-2043.

e-mail: edicleicarmo@iec.pa.gov.br

Recebido para publicação em 10/8/2004

Aceito em 27/9/2004
} 
Todos os pacientes receberam esclarecimento médico sobre os objetivos e riscos da pesquisa e após concordar em participar, assinaram um termo de consentimento livre e esclarecido e forneceram dados para preenchimento de ficha clínicoepidemiológica, de acordo com as recomendações do Comitê de Ética em Pesquisa do Instituto Evandro Chagas ao qual 0 estudo foi avaliado e aprovado (CEP/IEC-№ 003/2002).

Foram feitas coletas de amostra de sangue venoso e amostras de fluídos intra-oculares dos pacientes, estas realizadas no centro cirúrgico da Clínica de Olhos do Pará. Foram coletadas 9 amostras de humor vítreo e duas de humor aquoso, de nenhum paciente foi possível coletar amostras de ambos os fluidos. Todas as amostras foram testadas pela reação de imunofluorescência indireta (IFI) e ensaio imunoenzimático (ELISA). Na IFI, para pesquisa de IgG e IgM, utilizou-se antígenos comerciais liofilizados (Imunotoxo ${ }^{\circledR}$ (Biolab-Mérieux SA) e a técnica desenvolvida de acordo com a metodologia descrita por Camargo². 0 ponto de corte foi determinado como títulos $\geq 80$. No teste ELISA indireto para pesquisa de IgG e de captura para IgM e IgA, utlizou-se Kits comerciais (ELSA Platélia ${ }^{\circledR}$ Toxo IgG, IgM, IgA) . A técnica foi realizada e o ponto de corte determinado, segundo as recomendações do fabricante.

Na pesquisa de anticorpos séricos, a imunoglobulina $G$ foi detectada em todas as amostras por ambas as técnicas, enquanto a IgM não foi encontrada em nenhuma e a IgA em apenas 2 pacientes (Tabela1).

Na pesquisa de anticorpos no humor vítreo, seis pacientes apresentaram IgG (66,7\%). Nesses, a IgG foi detectada em 3 por ambas as técnicas, em 2 somente pelo ELSAe em 1 somente pela IFI. Năo foi detectado IgM em nenhuma das amostras de HV. Nas duas amostras de humor aquoso, observou-se presença de anticorpos IgG e ausência de IgM (Tabela 1). Em relação a pesquisa de anticorpos IgA no humor vitreo, esta classe foi detectada em 5 pacientes, todos apresentando também IgGintraocular e sérico. Dos 5 pacientes que apresentavam IgA, somente um apresentava IgA sérico. Nas duas amostras de humor aquoso anticorpos IgA também foram detectados, dos quais apenas uma apresentava IgA sérico (Tabela 1).

Desde 1982, 0 T. gondii vem sendo incriminado como 0 principal causador de uveítes no Brasil. Porém, devido a alta soroprevalência de anticorpos IgG anti-T. gondii, há dificuldade em se estabelecer o diagnóstico laboratorial da forma ocular de toxoplasmose, daí a necessidade de se procurar outra alternativas para realização desse diagnóstic ${ }^{6911}$.

No referido estudo, a positividade ( $66,7 \%)$ de IgG observada nas amostras de HV, corroboram os resultados obtidos por Canosa et $\mathrm{al}^{3}$, que avaliando 7 amostras de humor vítreo de pacientes com suspeita de toxoplasmose ocular, obtiveram resultados similares. Pela técnica de IFI, eles encontraram freqüência de positividade para $\operatorname{IgG}$ de $71,4 \%$, todos apresentando também IgG sérico. Turunen et a ${ }^{16}$ referem 0 IgG intra-ocular como um bom marcador nos casos de coriorretinites toxoplásmicas. A ausência de anticorpos IgM no soro e fluidos intra-oculares indica que nenhum dos pacientes estava na fase aguda da toxoplasmose.

\begin{tabular}{|c|c|c|c|c|c|c|}
\hline Paciente & Fuidos & $\begin{array}{l}\text { IF--IgG } \\
\text { (Título) }\end{array}$ & $\begin{array}{l}\text { IF-IgM } \\
\text { (Título) }\end{array}$ & $\begin{array}{l}\text { ELISA } \\
\text { IgG }\end{array}$ & $\begin{array}{c}\text { ELISA } \\
\text { IgM }\end{array}$ & $\begin{array}{c}\text { ELISA } \\
\text { IgA }\end{array}$ \\
\hline \multirow[t]{2}{*}{1} & soro & 80 & - & + & - & - \\
\hline & HV & - & - & + & - & - \\
\hline \multirow[t]{2}{*}{2} & soro & 2.560 & - & + & - & + \\
\hline & $\mathrm{HV}$ & 80 & - & + & - & + \\
\hline \multirow[t]{2}{*}{3} & soro & 1.280 & - & + & - & - \\
\hline & HV & - & - & + & - & + \\
\hline \multirow[t]{2}{*}{4} & soro & 2.560 & - & + & - & - \\
\hline & HV & 320 & - & + & - & + \\
\hline \multirow[t]{2}{*}{5} & soro & 10.240 & - & + & - & - \\
\hline & HV & 1.280 & - & + & - & + \\
\hline \multirow[t]{2}{*}{6} & soro & 2.560 & - & + & - & - \\
\hline & HV & 1.280 & - & - & - & + \\
\hline \multirow[t]{2}{*}{7} & soro & 10.240 & - & + & - & - \\
\hline & HV & - & - & - & - & - \\
\hline \multirow[t]{2}{*}{8} & soro & 1.280 & - & + & - & - \\
\hline & $\mathrm{HV}$ & - & - & - & - & - \\
\hline \multirow[t]{2}{*}{9} & soro & 320 & - & + & - & - \\
\hline & $\mathrm{HV}$ & - & - & - & - & - \\
\hline \multirow[t]{2}{*}{10} & soro & 10.240 & - & + & - & + \\
\hline & $\mathrm{HA}$ & 1.280 & - & + & - & + \\
\hline \multirow[t]{2}{*}{11} & soro & 2.560 & - & + & - & - \\
\hline & $\mathrm{HA}$ & $\mathrm{NR}$ & $\mathrm{NR}$ & + & - & + \\
\hline
\end{tabular}

+ (positivo; - negativo; IF (Ponto de corte $\geq 80$ ) ELISA IgG (Ponto de corte: 0,203 ); IgM (Ponto de corte: 0,154 - 0,192); IgA (Ponto de corte: 0,113 - 0,148); * HV ( Humor vítreo); HA (Humor aquoso)

Em relação a pesquisa de anticorpos IgA intra-ocular, os nosssos resultados demonstram, apesar de não serem estatísticamente significativos ( $\mathrm{P}>0,005$ - Teste Exato de Fisher), que esta imunoglobulina nesses fluidos pode ser importante marcador no diagnóstico de toxoplasmose ocular. Não há relatos na literatura a respeito de pesquisa de IgA anti-T. gondii no humor vítreo de pacientes com toxoplasmose ocular. Contudo, vários estudos relatam a importância da pesquisa de IgA no humor aquoso no diagnóstico de toxoplasmose ocular ${ }^{471013}$.

0 estudo de fluidos intra-oculares na rotina laboratorial de diagnóstico de toxoplasmose ainda pode ser considerado inviável, devido ao elevado grau de invasibilidade dos procedimentos de coleta, porém nos casos cujo diagnóstico clínico e sorológico são inconclusivos, a pesquisa de anticorpos e de DNA pela PCR nos fluidos intra-oculares, podem ser ferramentas alternativas para auxiliar o diagnóstico dessa forma de toxoplasmose.

\section{REFERÊNCIAS BIBLIOGRÁFICAS}

1. Abreu MT, Belfort Jr R, Oréfice, F. Toxoplasmose Ocular. In: Oréfice F, Belfort Jr R (eds) Uveítes, Roca, São Paulo, p. 211-230, 1987.

2. Camargo ME. Improved technique of indirect immunoofluorescence for serological diagnosis of toxoplasmosis. Revista do Instituto de Medicina Tropical de São Paulo 28: 211-214, 1964.

3. Canosa A, Gulh, F, Acevedo G, De Sánchez N, Marinkelle CJ. Anticuerpos específicos em humor vítreo em casos de toxoplasmosis ccular. Revista Latinoamericana de Microbiologia 27: 209-212, 1985. 
4. Garweg JG, Jacquier P, Boehnke M. Early Aqueous Humor Analysis In Patients With Human Ocular Toxoplasmosis. Journal of Clinical Microbiology 38: 996-1001, 2001.

5. Glasner PD, Silveira C, Kruszon-Moran D, Martins MC, Burnier Jr M, Silveira S, Camargo ME, Nussenblatt RB, Kaslow RA, Belfort Jr. R. An unusually high prevalence of ocular toxoplasmosis in Southern Brazil. American Journal of Ophthalmology 114: 136-144, 1992

6. Hay J, Dutton GN. Toxoplasma and the eye. British Medical Journal 310: 1021-1022, 1995

7. Katina JH, Oréfice F, Mineo JR. Anticorpos IgA específicos no soro e humor aquoso de pacientes com uveíte de provável etiologia toxoplásmica. Revista Brasileira de Oftalmologia 51: 21-26, 1992.

8. Montoya JG, Remington JS. Toxoplasmic chorioretinitis in the setting of acute acquired toxoplasmosis. Clinical Infectious Diseases 23: 277-282, 1996.

9. Nussenblatt RB, Belfort Jr. R. Ocular Toxoplasmosis: An old disease revisited. Journal of American Medical Association 271:304-307, 1994.

10. Ongkosuwito JV, Bosch-Driessen EH, Kijlstra A, Rothova A. Serologic Evaluation Of Patients With Primary And Recurrent Ocular Toxoplasmosis
For Evidence Of Recent Infection. American Journal of Ophthalmology 128: 407-412, 1999

11. Oréfice F. Síndrome Do Olho Vermelho. In: Marra UD (ed) Medicina Ambulatorial, Guanabara Koogan, Rio de Janeiro, p. 494-505, 1982.

12. Perkins ES. Ocular Toxoplasmosis. British Journal of Ophthalmology 51:1, 1973.

13. Ronday MJH, Ongkosuwito JV, Rothova A, Kijlstra A. Intraocular AntiToxoplasma gondii IgA antibody production in patients with ocular toxoplasmosis. American Journal of Ophthalmology 127: 294-300, 1999.

14. Silveira C, Belfort Jr R, Burnier R, Nussenblatt R. Acquired toxoplasmic infection as the cause of toxoplasmic retinochoroiditis in families. American Journal of Ophthalmology 106: 362-364, 1988.

15. Tenter AM, Heckeroth AR, Weiss LM. Toxoplasma gondii: from animals to humans. International Journal for Parasitology 30:1217-1258, 2000.

16. Turunen HJ, Leiniki PO, Saari KM. Demonstration of intraocular synthesis of immunoglobulin $\mathrm{G}$ toxoplasma antibodies for specific diagnosis of toxoplasmic chorioretinitis by enzyme immunoassay. Journal of Clinical Microbiology 17: 988-992, 1983. 